\title{
Sequence conservation and combinatorial complexity of Drosophila neural precursor cell enhancers
}

\author{
Thomas Brody', Wayne Rasband ${ }^{2}$, Kevin Baler ${ }^{2}$, Alexander Kuzin ${ }^{1}$, \\ Mukta Kundu ${ }^{1}$ and Ward F Odenwald*1
}

Address: ${ }^{1}$ Neural Cell-Fate Determinants Section, NINDS, NIH, Bethesda, Maryland, USA and ${ }^{2}$ Office of Scientific Director, IRP, NIMH, NIH, Bethesda, Maryland, USA

Email: Thomas Brody - brodyt@ninds.nih.gov; Wayne Rasband - wsr@nih.gov; Kevin Baler - kb263@cornell.edu;

Alexander Kuzin - kuzina@mail.nih.gov; Mukta Kundu - muktakundu@mail.nih.gov; Ward F Odenwald* - ward@codon.nih.gov

* Corresponding author

Published: I August 2008

BMC Genomics 2008, 9:37| doi:10.1/86/147|-2164-9-37|
Received: 25 April 2008

Accepted: I August 2008

This article is available from: http://www.biomedcentral.com/I47I-2/64/9/37I

(C) 2008 Brody et al; licensee BioMed Central Ltd.

This is an Open Access article distributed under the terms of the Creative Commons Attribution License (http://creativecommons.org/licenses/by/2.0), which permits unrestricted use, distribution, and reproduction in any medium, provided the original work is properly cited.

\begin{abstract}
Background: The presence of highly conserved sequences within cis-regulatory regions can serve as a valuable starting point for elucidating the basis of enhancer function. This study focuses on regulation of gene expression during the early events of Drosophila neural development. We describe the use of EvoPrinter and cis-Decoder, a suite of interrelated phylogenetic footprinting and alignment programs, to characterize highly conserved sequences that are shared among coregulating enhancers.
\end{abstract}

Results: Analysis of in vivo characterized enhancers that drive neural precursor gene expression has revealed that they contain clusters of highly conserved sequence blocks (CSBs) made up of shorter shared sequence elements which are present in different combinations and orientations within the different co-regulating enhancers; these elements contain either known consensus transcription factor binding sites or consist of novel sequences that have not been functionally characterized. The CSBs of co-regulated enhancers share a large number of sequence elements, suggesting that a diverse repertoire of transcription factors may interact in a highly combinatorial fashion to coordinately regulate gene expression. We have used information gained from our comparative analysis to discover an enhancer that directs expression of the nervy gene in neural precursor cells of the CNS and PNS.

Conclusion: The combined use EvoPrinter and cis-Decoder has yielded important insights into the combinatorial appearance of fundamental sequence elements required for neural enhancer function. Each of the 30 enhancers examined conformed to a pattern of highly conserved blocks of sequences containing shared constituent elements. These data establish a basis for further analysis and understanding of neural enhancer function.

\section{Background}

Studies over the last two decades have revealed that cisregulatory elements, i.e. enhancers, contain multiple DNA-binding sites for different transcription factors (TFs) that cooperatively function to direct the tissue specific expression of their associated genes [1]. DNA sequence comparisons of different co-regulating enhancers suggest that many of these enhancers rely on different combina- 
tions of TFs to achieve coordinate gene regulation [2]. For example, during early Drosophila neural development, combinatorial interaction of proneural basic helix-loophelix (bHLH) TFs with homeodomain proteins, regulate commitment and patterning of neural precursors [3-8].

Cross-species analysis of individual Drosophila enhancers, using EvoPrinter or conventional alignment based phylogenetic comparative analysis $[9,10]$ and the twelve sequenced Drosophila genomes, representing over 160 million years of collective evolutionary divergence, reveals that these enhancers are made up of clusters of highly conserved sequence blocks (CSBs), separated by less conserved sequences of variable length [11]. CSBs that are longer than 8-10 bp are likely to be made up of adjacent or overlapping DNA-binding sites for different TFs. For example, the Drosophila Krüppel central domain enhancer contains overlapping highly conserved binding sites for its known regulators [12-14,10]. Specifically, work from the Jäckle laboratory [14] has shown that one CSB of the central domain enhancer, 16 base pairs in length, contains overlapping binding sites for the antagonistic Bicoid activator and the Knirps repressor TFs.

In order to initiate the functional dissection of CSBs that make up neural precursor gene enhancers and to gain a better understanding of their architecture in terms of the substructure of their constituent sequence elements, we have developed a multi-step protocol (collectively known as cis-Decoder) that allows for the rapid identification of short 6 to 14 bp DNA elements, termed cis-Decoder tags ( $c \mathrm{DTs}$ ), within enhancer CSBs; these $c \mathrm{DTs}$ are shared between CSBs of two or more enhancers with either related or divergent functions [11]. To discover enhancer type-specific elements that regulate gene expression in neural precursor cells - including genes expressed in early delaminating CNS neuroblasts (NBs) and the proneural clusters and sensory organ precursors of the PNS - we have performed cis-Decoder analysis of CSBs from in vivo characterized enhancers. For early CNS development, we have selected the previously described enhancers of six genes that activate expression in early delaminating CNS NBs: deadpan (dpn), hunchback (hb), nerfin-1, scratch (scrt; the SA enhancer), snail (sna) and worniu (wor) (Table 1) [15-18]. For the cis-regulatory regions that drive expression in the proneural clusters (PNCs) and sensory organ precursors (SOPs) of the PNS we selected the in vivo characterized enhancers for bearded (brd), deadpan (dpn), rhomboid (rho), scrt and sna (Table 1) [19-24].

Our analysis of the CSBs from these characterized enhancers has identified known TF DNA-binding sites and novel sequences of as yet unknown function. Enhancer typespecific sequence elements within CSBs appear in different combinations and contexts in enhancers of co-regu- lated genes. The information gained from cis-Decoder analysis of the neural precursor cell enhancer CSBs was used to discover a novel co-regulating enhancer that directs Drosophila nervy expression. Our studies indicate that although specific core DNA-binding sites (such as those for bHLH and homeodomain TFs) are enriched in enhancers of co-regulated genes, enhancer-binding specificity is most likely conferred through sequences that flank the consensus core docking sites. The fact that shared sequence elements of co-regulated enhancers reside in different combinations and positional ordering within each of the enhancers, suggests that their combined presence but not necessarily their relative positions is required for cis-regulatory function.

\section{Results and discussion \\ Neural precursor cell enhancers share highly conserved core sequence elements}

To determine the extent to which neural precursor cell enhancers share highly conserved sequence elements, we performed cis-Decoder analysis of in vivo characterized enhancers (Table 1) [15-28]. Our analysis revealed the presence of both novel elements and sequences that contained consensus DNA-binding sites for known regulators of early neurogenesis. Table 2 lists $c$ DTs shared by multiple CNS or PNS neural precursor cell enhancers. None of the elements shown were present in our collection of 819 CSBs from in vivo characterized mesodermal enhancers, thus ensuring their enrichment in neural enhancers. Highlighted are consensus binding sites for known TFs; basic Helix-Loop Helix (bHLH) factors and Suppressor of Hairless $[\mathrm{Su}(\mathrm{H})]$, respectively acting in proneural and neurogenic pathways [7]; Antennapedia class homeodomain proteins [29], identified by their core ATTA binding sequence, and the ubiquitously expressed Pbx- (Pre-B Cell Leukemia TF) class homeodomain protein Extradenticle, a cofactor of many TFs [30], identified by the core binding sequence of ATCA. More than half the conserved $c$ DTs were novel, without identified interacting proteins. Many of the CSBs consisted of 8 or more bp, and often contained core sequences identical to binding sites for known factors as well as other core sequences that aligned with shorter novel $c$ DTs, suggesting that the longer $c$ DTs may contain core recognition sequences for two or more TFs.

Most $c$ DTs discovered in this analysis represent elements that are shared pairwise, i.e., by only two of the NB enhancers examined (see the website for a list of CDTs that are shared by only two of the enhancers examined). The fact that the majority of $c$ DTs are shared two ways, with only a small subset of sequences being shared three or more ways, suggests that the cis-regulation of early neural precursor genes is carried out by a large number of factors acting combinatorially and/or that many of the identified $c$ DTs may in fact represent interlocking sites for multiple 
Table I: Drosophila enhancers included in the cis-Decoder analysis

\begin{tabular}{|c|c|c|c|}
\hline Enhancer & \# CSBs & Location*/Size in bp & References \\
\hline \multicolumn{4}{|l|}{ CNS Neuroblast } \\
\hline deadpan & 32 & -1405 to $-2772 / 1367$ & {$[15]$} \\
\hline hunchback & 26 & -36 to $-1270 / 1224$ & {$[16]$} \\
\hline nerfin-I & 29 & -1529 to $-160 / 1369$ & A. Kuzin (personal com.) \\
\hline scratch & 48 & -10867 to $-4796 / 6069$ & {$[15]$} \\
\hline worniu & 106 & -51 to $-6940 / 5989$ & {$[17]$} \\
\hline snail & 26 & $-244-$ to $-1138 / 869$ & {$[18]$} \\
\hline \multicolumn{4}{|c|}{ PNS Precursor Cell } \\
\hline achaete (DC) & 28 & -5584 to $-7725 / 2|4|$ & {$[19]$} \\
\hline $\operatorname{amos}(3.5)$ & 56 & -2397 to $+102 / 2499$ & {$[20]$} \\
\hline atonal (F:2.6) & 60 & -2807 to $+175 / 2982$ & {$[21]$} \\
\hline bearded & 20 & -589 to $+25 / 614$ & {$[22]$} \\
\hline Pray For Elves & 27 & +2236 to $+2711 / 475$ & {$[23]$} \\
\hline charlatan & 18 & $+\mid 5440$ to $+\mid 7758 / 2318$ & {$[23]$} \\
\hline deadpan & 18 & $-4 \mid 66$ to $-4677 / 51 \mid$ & {$[15]$} \\
\hline ETS-domain lacking & 15 & +998 to $+2174 / 1176$ & [23] \\
\hline rhomboid & 21 & -6669 to $-8419 / 1720$ & [23] \\
\hline schizo & 20 & +311166 to $+32661 / 1595$ & {$[23]$} \\
\hline scute & 7 & -2562 to $-30 \mid 5 / 453$ & [24] \\
\hline scratch & 21 & -3898 to $-2000 / 1998$ & {$[15]$} \\
\hline Snail & 17 & -543 to $+40 / 583$ & {$[18]$} \\
\hline \multicolumn{4}{|l|}{$E(s p l)$ enhancers } \\
\hline HLHm3 & 32 & -2176 to $+177 / 2353$ & {$[25]$} \\
\hline HLH m5 & 38 & -1743 to $+2 \mid / / 767$ & [25] \\
\hline HLH m7 & 20 & -770 to $-26 / 744$ & {$[25]$} \\
\hline$E(s p l) m 8$ & 22 & -773 to $+|88 / 96|$ & {$[25]$} \\
\hline$H L H m \beta$ & 20 & -1012 to $+81 / 1093$ & {$[25]$} \\
\hline$H L H m \gamma$ & 25 & -49 to $-853 / 8 \mid 4$ & [25] \\
\hline$H L H m \delta$ & 20 & -1634 to $+25 / 1659$ & {$[25]$} \\
\hline$E(s p l) m 2$ & 36 & -1659 to $+48 / 1707$ & [26] \\
\hline$E(s p l) m 4$ & 24 & -157 to $-1056 / 899$ & {$[27,28]$} \\
\hline$E(s p l) m 6$ & 26 & -880 to $+7 / 887$ & {$[26]$} \\
\hline$E(s p l) m \gamma$ & 26 & -1718 to $-40 / 1678$ & {$[26]$} \\
\hline
\end{tabular}

*Relative to transcription start site

factors, and the exact orientation and spacing of these sites may differ among enhancers.

\section{Neural specific cDTs that contain bHLH TF DNA-binding sites}

During Drosophila neurogenesis, bHLH proteins function as proneural TFs to initiate neurogenesis in both the central and peripheral nervous system. TFs encoded by the achaete-scute complex function in both systems, while the related Atonal bHLH protein functions exclusively in the PNS [31]. Different proneural bHLH TFs, acting together with the ubiquitous dimerization partner Daughterless, bind to distinct E-boxes that contain different core sequences [32]. In addition to the core recognition sequence, flanking bases are important to the DNA binding specificity of bHLH factors [33].

One of the principle observations of this study was that the core central two bases of the hexameric E-box DNAbinding site (CANNTG; core bases are bold throughout) were conserved in all the species used to generate the EvoPrint. All of the enhancers included in this study contained one or more conserved bHLH-binding sites (Table 3 ), with NB and PNS enhancers averaging 3.9 and 4.1 binding sites respectively. More than a third of the core bases in NB bHLH sites contained a core GC sequence, and more than a third of the core bases in PNS bHLH sites contained either a core GC or a GG sequence. The most common E-box among the NB CSBs was CAGCTG with 14 sites in four of the six enhancers. The CAGCTG and CAGGTG E-boxes are high-affinity sites for Achaete/Scute bHLH proteins $[22,34]$. However the CAGCTG site itself is not specific to NB enhancers, as evidenced by its presence in four of the mesodermal enhancer CSBs characterized previously [11]. The most common bHLH-binding site among PNS enhancers was also the CAGCTG E-box with 11 occurrences in six of the 13 enhancers. In contrast, the most common bHLH motif in enhancers of the E(spl)-complex [25-28] was CAAGTG (data not shown), with 16 occurrences in 8 of the 11 enhancers. CAGGTG, 
Table 2: Conserved neural specific sequence elements within two or more neural precursor cell enhancers

\begin{tabular}{|c|c|c|c|c|c|c|c|c|c|c|c|c|c|c|c|c|c|c|c|}
\hline \multirow{2}{*}{$\begin{array}{l}\text { CDTs } \\
\text { Gene-> }\end{array}$} & \multicolumn{6}{|c|}{ CNS Neural Precursor Cell Enhancers } & \multicolumn{13}{|c|}{ PNS Neural Precursor Cell Enhancers } \\
\hline & $d p n$ & $h b$ & $n f-I$ & scrt & sna & wor & $a c$ & amos & ato & brd & char & $d p n$ & edl & pfe & rho & $s c$ & scrt & siz & sna \\
\hline ACTTGATT & I & - & - & 1 & - & - & - & - & - & - & - & - & - & - & - & - & - & - & - \\
\hline TTTGAATTA & - & 1 & - & - & - & 2 & - & - & - & - & - & - & - & - & - & - & - & - & - \\
\hline TAATTGAT & - & - & - & - & - & 2 & - & - & - & - & - & - & - & - & - & - & - & - & - \\
\hline TGATTTCT & - & - & I & - & 1 & 1 & - & - & - & - & - & - & - & - & - & - & - & - & - \\
\hline AAATTAGT & 1 & - & - & - & - & 2 & - & - & - & - & - & - & - & - & - & - & - & - & - \\
\hline AAGTGCAA & - & - & - & 2 & - & 1 & - & - & - & - & - & - & - & - & - & - & - & - & - \\
\hline AAATTAGT & I & - & - & - & - & 2 & - & - & - & - & - & - & - & - & - & - & - & - & - \\
\hline ACAGCTGT & - & - & 1 & 1 & - & - & - & - & - & - & - & - & - & - & - & - & - & - & - \\
\hline TACGTGT & - & - & - & 2 & - & 1 & - & - & - & - & - & - & - & - & - & - & - & - & - \\
\hline GATTTAC & I & - & - & - & - & 2 & - & - & - & - & - & - & - & - & - & - & - & - & - \\
\hline CGGCGTC & - & - & 2 & - & - & 1 & - & - & - & - & - & - & - & - & - & - & - & - & - \\
\hline CAGGATA & - & - & - & 2 & 1 & - & - & - & - & - & - & - & - & - & - & - & - & - & - \\
\hline CACTTCA & I & - & - & - & - & 2 & - & - & - & - & - & - & - & - & - & - & - & - & - \\
\hline AATGTGT & 2 & - & 1 & - & - & - & - & - & - & - & - & - & - & - & - & - & - & - & - \\
\hline AATGCAC & - & - & 2 & - & 1 & - & - & - & - & - & - & - & - & - & - & - & - & - & - \\
\hline AACATAA & - & - & 1 & - & - & 2 & - & - & - & - & - & - & - & - & - & - & - & - & - \\
\hline AAAATGC & - & 2 & - & - & - & 1 & - & - & - & - & - & - & - & - & - & - & - & - & - \\
\hline TGATCCA & I & - & - & - & 1 & - & - & - & - & - & - & - & - & - & - & - & - & - & - \\
\hline GCACGA & 2 & - & - & 1 & - & - & - & - & - & - & - & - & - & - & - & - & - & - & - \\
\hline GATTCC & - & - & 2 & 1 & - & - & - & - & - & - & - & - & - & - & - & - & - & - & - \\
\hline GAGTGC & - & - & 1 & 1 & - & 1 & - & - & - & - & - & - & - & & - & - & - & - & - \\
\hline ATGGC & - & - & - & 2 & - & 1 & - & - & - & - & - & - & - & - & - & - & - & - & - \\
\hline CTAAGC & I & - & I & 1 & - & 1 & - & - & - & - & - & - & - & - & - & - & - & - & - \\
\hline AATCCC & - & 1 & - & - & - & 3 & - & - & - & - & - & - & - & - & - & - & - & - & - \\
\hline CACCCG & - & - & - & - & 2 & 2 & - & - & - & - & - & - & - & - & - & - & - & - & - \\
\hline AGATAT & I & - & - & - & 1 & 1 & - & - & - & - & - & - & - & - & - & - & - & - & - \\
\hline AGCTTA & - & 1 & I & - & - & 1 & - & - & - & - & - & - & - & - & - & - & - & - & - \\
\hline GGGGCA & 1 & - & - & 1 & - & 1 & - & - & - & - & - & - & - & - & - & - & - & - & - \\
\hline TTTTAATTA & - & - & - & 1 & - & 1 & 1 & - & - & - & - & - & - & - & - & - & - & - & - \\
\hline CAAATTAG & I & - & - & - & - & 2 & 1 & - & - & - & - & - & - & - & - & - & - & - & - \\
\hline ACAAACAA & - & 1 & I & - & - & 1 & - & I & - & - & - & - & - & - & - & - & - & - & - \\
\hline AGTTATTA & 2 & - & - & - & - & 1 & - & - & - & - & - & - & - & - & - & - & - & - & 1 \\
\hline TTTGATTT & I & 1 & - & - & 1 & - & - & - & - & - & - & - & - & 1 & - & - & - & - & - \\
\hline AACAGCTG & - & - & 3 & 1 & - & - & - & - & - & - & 1 & - & - & - & - & - & - & - & - \\
\hline AAATATG & 1 & - & 1 & 1 & - & 1 & - & - & I & - & - & - & - & - & - & - & - & - & - \\
\hline TATTGAA & 1 & - & - & 2 & - & - & - & - & - & - & 1 & - & - & - & - & - & - & - & \\
\hline ATATTTG & - & - & - & 2 & - & 1 & - & - & 1 & & - & - & - & - & - & - & - & - & - \\
\hline AAACTAA & - & 2 & - & - & - & 1 & - & - & - & 1 & - & - & - & - & - & - & - & - & - \\
\hline GTGTAAA & 1 & 1 & - & - & - & 1 & - & - & - & 1 & - & - & - & - & - & - & - & - & - \\
\hline TTGATCC & 1 & - & - & 1 & - & 1 & - & - & - & - & & - & - & - & - & - & 1 & - & - \\
\hline GGAAAAA & - & - & 1 & 1 & - & 1 & - & - & - & - & - & - & - & - & - & - & - & 1 & - \\
\hline CACCCCA & 1 & - & 1 & 1 & - & - & - & - & - & - & 1 & - & - & - & - & - & - & - & - \\
\hline CCACCCC & - & 1 & I & 1 & - & I & - & - & - & - & 2 & - & - & - & - & - & - & - & - \\
\hline ACCCCA & - & - & 1 & 1 & 1 & 2 & - & - & - & - & 1 & - & - & - & - & - & - & - & 1 \\
\hline ATTAGTT & - & - & - & 1 & - & 2 & - & - & - & 1 & - & - & - & - & - & - & - & - & - \\
\hline AGCTGAC & I & - & 1 & - & - & 1 & - & - & - & - & - & - & - & - & - & - & I & - & - \\
\hline ACAATGA & - & - & 1 & 1 & 1 & - & - & - & 1 & - & - & - & - & - & - & - & - & - & - \\
\hline TCCCAC & I & - & - & - & - & 1 & - & - & - & 1 & - & - & - & - & - & - & - & - & - \\
\hline TTCCCAC & 2 & - & - & - & - & - & - & - & - & - & - & 1 & - & - & - & - & - & - & - \\
\hline GTTCCCA & I & - & - & - & - & 2 & - & - & - & - & - & 1 & - & - & - & - & - & - & - \\
\hline TCCCAC & 2 & - & - & - & - & 1 & - & - & - & 1 & - & 1 & - & - & - & - & - & - & - \\
\hline CCATTAT & - & - & - & 1 & - & 1 & - & - & - & - & - & - & - & - & - & - & - & 1 & - \\
\hline TGATCC & 2 & - & - & 1 & - & 1 & - & - & - & - & - & - & - & & - & - & 1 & & - \\
\hline CACGAT & 2 & - & - & - & - & I & - & - & - & - & - & - & - & - & - & - & I & - & - \\
\hline ACCTTG & 1 & - & - & 2 & - & - & - & - & - & - & 1 & - & - & - & - & - & - & - & - \\
\hline CTAAAC & & 1 & 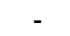 & 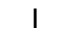 & l & & - & 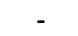 & & 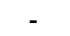 & & 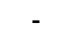 & - & 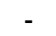 & 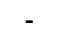 & 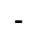 & - & 1 & \\
\hline
\end{tabular}


Table 2: Conserved neural specific sequence elements within two or more neural precursor cell enhancers (Continued)

\begin{tabular}{|c|c|c|c|c|c|c|c|c|c|c|c|c|c|c|c|c|c|c|c|}
\hline GTGATC & & & - & $T$ & $T$ & & - & - & - & - & - & $T$ & & - & - & - & - & - & \\
\hline САСТCA & 1 & - & - & I & - & I & - & - & - & 1 & - & - & - & - & - & - & - & - & - \\
\hline ACCTGA & I & I & - & - & - & I & - & - & - & - & - & - & - & - & - & - & - & - & 1 \\
\hline AGCACGTGCC & - & - & - & - & - & I & - & - & 1 & - & - & - & - & - & 1 & - & - & - & - \\
\hline CAGCAGCTG & - & - & - & 2 & - & - & - & - & - & - & 1 & - & - & - & - & - & - & - & - \\
\hline AATTAGC & - & I & - & - & - & I & 2 & I & - & - & - & - & - & - & 1 & - & - & - & - \\
\hline CGTGCCA & 1 & - & - & 2 & - & I & - & 1 & 1 & - & - & - & - & - & - & - & - & - & - \\
\hline TCACACA & 1 & - & I & - & I & - & - & - & 1 & - & - & - & 1 & - & - & - & - & - & - \\
\hline AAAGTT & 1 & - & - & 1 & I & I & - & - & - & - & - & I & - & - & - & - & I & - & \\
\hline TCAATAA & I & - & - & 1 & - & I & - & I & - & - & - & - & - & - & 1 & - & - & I & - \\
\hline GCACTTG & - & - & - & 3 & - & - & 1 & - & - & - & - & - & - & - & - & I & - & - & - \\
\hline CACTTGC & - & - & - & 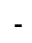 & - & 2 & 2 & - & - & - & - & - & - & - & - & - & - & - & - \\
\hline GGCTAA & - & I & - & 2 & I & & I & I & - & - & - & - & - & - & 1 & - & - & - & - \\
\hline CGTGCC & I & - & I & 2 & - & 2 & - & I & 3 & - & - & - & - & - & I & I & - & - & - \\
\hline CACGTC & - & - & - & II & - & I & - & - & 1 & 1 & - & - & - & - & - & - & 1 & I & - \\
\hline CAGCTT & - & - & I & - & - & - & - & - & 1 & - & - & - & - & - & 1 & - & I & - & - \\
\hline CAGGTT & I & - & - & 1 & - & I & - & - & - & - & 1 & - & - & - & 1 & - & - & - & I \\
\hline CGGTTT & - & - & - & - & - & I & I & - & 1 & - & - & - & - & - & - & - & - & I & - \\
\hline GCTTCC & I & - & - & I & - & I & I & - & 1 & - & - & - & - & - & 1 & - & - & - & - \\
\hline GTTTGA & - & - & - & 2 & - & 2 & I & 1 & 1 & - & - & - & - & - & - & - & - & - & - \\
\hline TCACCT & - & - & - & 1 & I & - & 1 & - & - & - & - & I & - & - & - & - & I & - & - \\
\hline AAAAACT & - & - & - & - & - & I & I & - & - & 1 & - & 1 & - & - & - & - & - & - & - \\
\hline AACACGC & - & - & - & - & - & I & I & 1 & - & - & - & - & - & - & 1 & - & - & - & - \\
\hline CAAACAA & - & I & - & - & - & I & - & I & 1 & - & - & - & - & - & - & - & - & I & \\
\hline GTCAATA & 1 & - & - & - & - & 2 & - & I & 1 & - & - & - & - & - & I & - & - & - & - \\
\hline TGCAGCTG & - & - & - & - & - & I & - & - & - & - & 1 & - & 2 & I & 1 & - & - & - & - \\
\hline CGGCAGCTG & - & - & - & I & - & - & - & - & - & - & 1 & - & 1 & - & - & - & - & - & - \\
\hline AATTCATA & I & - & - & - & - & - & - & I & - & - & - & 1 & . & I & - & - & - & - & - \\
\hline ATTAGCAT & - & - & - & - & - & - & - & I & 1 & - & - & - & - & - & - & - & - & - & - \\
\hline AAATTAGC & - & 1 & - & I & - & I & 2 & - & - & - & - & - & - & - & - & - & - & - & - \\
\hline TTATTACA & - & - & - & 1 & - & - & - & - & 2 & - & - & - & - & - & - & - & - & - & - \\
\hline TAATTGCC & - & - & - & - & - & - & - & - & - & - & - & - & - & - & 2 & - & - & - & - \\
\hline GCAGCTGT & - & - & - & - & - & - & - & - & - & - & I & - & - & - & 1 & - & I & - & - \\
\hline TACCTGG & - & - & - & I & I & - & I & - & - & - & - & - & - & - & - & - & I & - & - \\
\hline CACGTGCT & - & - & - & - & - & - & - & - & 1 & - & - & - & - & - & 1 & - & - & - & - \\
\hline CAAACG & - & - & - & - & - & I & 1 & I & - & I & - & - & - & - & - & - & - & - & - \\
\hline ССТАCT & - & - & - & - & - & - & - & - & I & - & I & I & - & - & - & - & - & - & - \\
\hline CCTGTC & - & - & - & - & I & - & - & 1 & - & - & - & - & - & - & - & - & 1 & - & 1 \\
\hline TGAGAA & - & - & - & - & - & - & I & - & - & - & - & 3 & - & - & - & - & - & - & \\
\hline CGCGAG & - & - & I & - & - & - & - & - & - & - & - & - & - & - & - & - & 1 & 2 & \\
\hline CGCGTGGCA & - & - & - & - & - & - & - & I & - & - & - & - & - & - & - & I & I & - & - \\
\hline GCTTTCAATTA & - & - & - & - & - & - & I & - & - & - & - & - & - & - & I & - & - & - & - \\
\hline CAGCTGCAATT & - & - & - & - & - & - & - & - & - & - & - & - & . & I & 1 & - & - & - & - \\
\hline GCACGTGTGC & - & - & - & - & - & - & - & - & - & I & - & - & - & - & - & - & - & - & I \\
\hline CACCAAATGG & - & - & - & - & - & - & - & - & I & - & - & - & - & - & - & - & - & - & 1 \\
\hline CACGTGCAA & - & - & - & - & - & - & - & - & - & 1 & - & 1 & - & - & - & - & - & - & - \\
\hline GCAGGTGTA & - & - & - & - & - & - & - & - & 1 & - & - & - & - & - & - & 1 & - & - & - \\
\hline TGGTGGTGG & - & - & - & - & - & - & - & - & - & - & - & 2 & - & - & - & - & - & - & 1 \\
\hline TTGAAAAA & - & - & - & - & - & - & - & - & 1 & - & I & - & - & I & - & - & - & - & - \\
\hline ATTGCAGC & - & - & - & - & - & - & - & 1 & - & - & - & - & - & I & 1 & - & - & - & - \\
\hline ATTGAAAA & - & - & - & - & - & - & - & - & 2 & - & I & - & 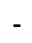 & - & - & - & - & - & - \\
\hline GACAACA & - & - & - & - & - & - & - & - & 1 & 1 & - & - & - & - & 1 & - & - & - & - \\
\hline GAATTGA & - & - & - & - & - & - & I & I & - & - & - & I & - & - & - & - & - & - & - \\
\hline СТTTCAA & - & - & - & - & - & - & I & 2 & - & - & I & - & - & - & 1 & - & - & - & - \\
\hline GTGAGAA & - & - & - & - & - & & 1 & - & - & - & - & 2 & - & - & - & - & - & - & \\
\hline ACGTGTG & - & - & - & - & - & - & I & - & I & I & - & - & - & - & - & - & - & I & I \\
\hline AACCACC & - & - & - & - & - & - & - & - & - & - & I & I & - & - & - & - & - & - & 1 \\
\hline ACCCCTA & - & - & - & . & - & & - & - & & 1 & I & - & & - & - & I & - & - & \\
\hline ACGGAAG & - & - & - & - & - & - & I & - & - & - & - & - & - & - & 1 & - & I & - & \\
\hline AGATTAT & - & - & - & - & - & - & - & 1 & I & - & - & - & 1 & - & - & - & - & - & - \\
\hline AGCGTCA & . & - & - & - & - & - & I & - & - & - & I & - & & - & - & & & - & \\
\hline
\end{tabular}


Table 2: Conserved neural specific sequence elements within two or more neural precursor cell enhancers (Continued)

\begin{tabular}{|c|c|c|c|c|c|c|c|c|c|c|c|c|c|c|c|c|c|c|c|}
\hline CATCTGT & - & - & - & - & - & - & - & - & - & - & - & - & $T$ & - & - & - & $T$ & $T$ & - \\
\hline CAGCAC & - & - & - & - & - & - & - & - & 3 & - & - & - & - & - & - & - & 3 & - & - \\
\hline GTAGGA & - & - & - & - & - & - & - & - & - & - & 2 & I & - & - & - & - & - & - & - \\
\hline CCGTGC & - & - & - & - & - & - & - & I & - & - & - & - & - & - & 1 & - & I & - & - \\
\hline CGCCTC & - & - & - & - & - & - & - & - & - & - & I & - & - & - & I & - & I & - & - \\
\hline GAAAGC & - & - & - & - & - & - & I & - & 1 & - & 1 & - & - & - & - & I & - & I & - \\
\hline GAGTCA & - & - & - & - & - & - & - & I & - & I & - & - & - & - & - & - & - & - & I \\
\hline TAGCCA & - & - & - & - & - & - & I & 2 & - & I & I & - & - & - & - & - & - & - & - \\
\hline TCTATT & - & - & - & - & - & - & I & I & - & - & - & - & - & - & - & - & - & - & I \\
\hline ATCTAA & - & - & - & - & - & - & I & - & 2 & - & - & - & - & - & - & - & - & - & - \\
\hline
\end{tabular}

previously shown to be an Atonal DNA-binding site [32], was also common in $\mathrm{E}(\mathrm{spl})$ enhancers, with 9 occurrences in 8 of the 13 enhancers, but was less prevalent among NB enhancers. The CAGGTG box was also overrepresented in PNS and E(spl) enhancers relative to its appearance in NB enhancers, and it was also present in four of the characterized mesodermal enhancer CSBs. The CAGATG box was present six times among PNS enhancers but not at all among NB enhancers. Thus there appears to be some specificity of E-boxes in the different enhancer types. The fact that each of these E-boxes is conserved in all the species in the analysis, suggests that there is a high degree of specificity conferred by the E-box core sequence.

Our analysis also reveals that not only are the core bases of E-boxes shared between similarly regulated enhancers, but bases flanking the E-box were also found to be highly conserved and are also frequently shared by these enhancers. Among the E-boxes found in CSBs of NB enhancers (many are illustrated in Table 2) aaCAGCTG (core bases of E-box are bold, flanking bases lower case) is repeated three times in nerfin-1 and once in scrt; gCACTTG is repeated three times in scrt; CAGCTGCA is repeated twice in wor, and CAGCTGctg is repeated twice in scrt (see Fig 1). In the dpn CNS NB enhancer, the E-box CAGCTG is found twice, separated by a single base (CAGCTGaCAGCTG). None of these sequences were present in mesodermal enhancers examined, but each is found in PNS enhancers; CAGCTGCA is repeated multiple times among PNS enhancers. Among the conserved PNS enhancer E-boxes (CAAATGca, gcCAAATG, cacCAAATGg, CACATGttg, gCACGTGtgc， ttgCACGTG， agCACGTGcc， aCAGATG， ggCAGATGt, CAGCTGccg, CAGCTGcaattt, gCAGGTGta and cCAGGTGa) each, including flanking bases, is found in two or three PNS enhancers, and these are distributed among all 13 enhancers. Of these, only agCACGTGcc, CAGCTGccg, cCAGGTGa were found once in our sample of neuroblast enhancers and none were found in our sample of mesodermal enhancers. The sequence aaCAAGTG is found in $4 \mathrm{E}(\mathrm{spl})$ complex enhancers, those for $E(\mathrm{spl}) m 8$, $m \gamma, H L H m \delta$ and $m 6$, and the sequence aCAGCTGc is found twice in $E(\mathrm{spl}) m 8$ and once in $m 4$ and $m 6$; neither sequence was found in our mesodermal enhancers. There- fore, although a given hexameric sequence may often be shared by all three types of enhancers, NB, PNS and $\mathrm{E}(\mathrm{spl})$, when flanking bases are taken into account there appears to be enhancer type-specific enrichment for different E-boxes.

\section{Neural specific cDTs that contain Antennapedia class homeodomain DNA-binding sites}

Antennapedia class homeodomain proteins play essential roles in multiple aspects of neural development including cell proliferation and cell identity [35]. The segmental identity of Drosophila NBs is conferred by input from TFs encoded by homeotic loci of the Antennapedia and bithorax complexes [36-38]. For example, ectopic expression of $a b d-A$, which specifies the NB6-4a lineage, down-regulates levels of the G1 cyclin, CycE [38]. Loss of Polycomb group factors has been shown to lead to aberrant derepression of posterior Hox gene expression in postembryonic NBs, which causes NB death and termination of proliferation in the mutant clones [39].

We have examined the enhancer-type specificity of sequences flanking the Antennapedia class core DNAbinding sequence, ATTA [40]. Nearly $25 \%$ of the NB and PNS CSBs examined in this study contain this core recognition sequence. ATTA-containing sites were found multiple times in selected NB and PNS enhancers (Figure 1). The cis-Decoder analysis identified 18 different neural specific ATTA containing $c$ DTs that were exclusively shared by two or more PNS enhancers or CNS enhancers and 10 were found to be shared between PNS and CNS. The most common $c$ DT, ATTAgca, was shared by two CNS and two PNS enhancers (Figure 1; consensus homeodomain-binding sites are bold, flanking sequence lower case). In addition, 6 homeodomain-binding site $c \mathrm{DTs}$ were found twice in wor CSBs, aATTAccg, tttgaATTA, aatcaATTA, ATTAATctt and aaacaaATTAg, but not in other CNS or PNS enhancer CSBs. In some cases these $c$ DTs were found repeated in given enhancer CSBs. Only one of these $c$ DTs aligned with CSBs of enhancers of the $\mathrm{E}(\mathrm{spl})$ complex. Given that 2/3 of the occurrences of HOX sites in these promoters can be accounted for by $c$ DTs whose flanking sequences are shared between enhancers, it is 


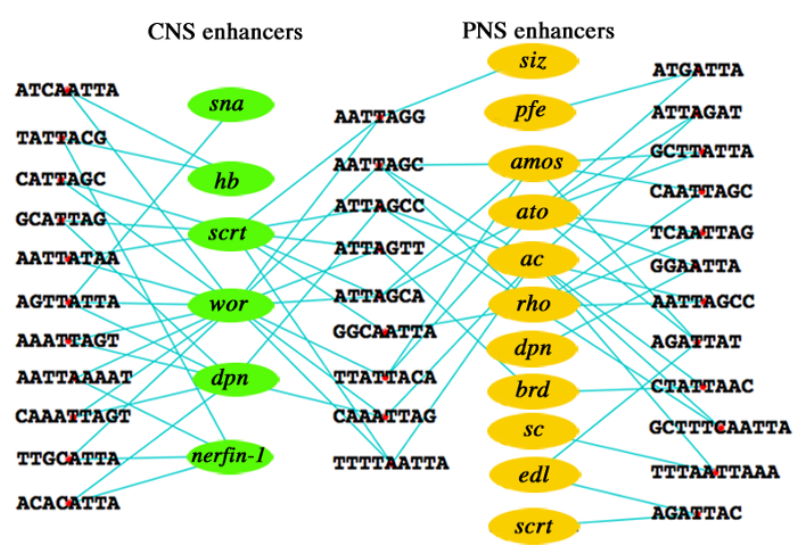

Figure I

Shared cDTs that contain Antennapedia class homeodomain protein DNA-binding sites within CNS and PNS neural precursor cell enhancers. Shown is a Cytoscape display of CNS and PNS neural precursor cell enhancer cDTs that contain core ATTA homeodomain DNA-binding sites. CDTs flanking the enhancer names are shared by CSBs of a single enhancer type, and CDTs positioned between the enhancer names are shared in common by CSBs of the two different enhancer types. Only CDTs of 7 or more bases shared by two or more enhancers are portrayed.

unlikely that the appearance of these shared sequences occurs by chance.

In summary, the appearance of Hox sites in the context of conserved sequences shared by functionally related enhancers suggests that the specificity of consensus homeodomain-binding sites is conferred by adjacent bases, either through recognition of adjacent bases by the TF itself or in conjunction with one or more co-factors.

Neural specific cDTs that contain Pbx/Extradenticle sites Examination of the cDTs from Drosophila NB and PNS enhancers revealed that many contained the core $\mathrm{Pbx} /$ Extradenticle docking site ATGA [41,42]. In Drosophila, Extradenticle has been shown to have Hox-dependent and independent functions [43]. Studies have also shown that Pbx factors provide DNA-binding specificity for homeodomain TFs, facilitating specification of distinct structures along the body axis [43]. In the CNS enhancers of Drosophila, most predicted Pbx/Extradenticle sites are not, however, found adjacent to Hox sites.

Our analysis revealed that 8 of the Pbx motifs were shared between CNS and PNS enhancer types, and 16 were shared between similarly expressed enhancers (Figure 2), thus indicating that there appears to be some degree of specificity to Pbx site function when flanking bases are taken into account. Three of the Pbx binding-site containing elements also exhibit ATTA Hox sites: 1) the dodecamer GATGATTAATCT (Pbx site is ATGA, Hox sites in bold) shared by the PNS enhancers edl and amos (references in Table 1), contains a homeodomain ATTA site that overlaps the Pbx site by a single base, and 2) the smaller heptamer ATGATTA, shared by $p f e$ and ato, likewise contains a homeodomain ATTA site (bold) that overlaps ATGA Pbx site by a single base. Adjacent Hox and Pbx sites have been documented to facilitate synergy between the two factors [44]. Taken together our findings suggest that, as with homeodomain-binding sites, the conserved bases flanking putative $\mathrm{Pbx}$ sites are functionally important. These flanking bases are likely to confer different DNAbinding affinities for $\mathrm{Pbx}$ factors or are required for binding of other TFs.

\section{Neural specific cDTs that contain Suppressor of Hairless binding sites}

Also indicating a degree of biological specificity of enhancer types is the distribution of Suppressor of Hairless $\mathrm{Su}(\mathrm{H})$ binding sites among neural enhancers. $\mathrm{Su}(\mathrm{H})$ is the Notch pathway effector TF of Drosophila [45]. The members of the $\mathrm{E}(\mathrm{spl})$ complex, both the multiple basic helix-loop-helix (bHLH) repressor genes and the Bearded family members, have been shown to be $\mathrm{Su}(\mathrm{H})$ dependent $[23,26]$. The consensus in vitro DNA binding site for $\mathrm{Su}(\mathrm{H}$ ) is RTGRGAR (where $\mathrm{R}=\mathrm{A}$ or $\mathrm{G}$ ) [25]. Notch signaling via $\mathrm{Su}(\mathrm{H})$ occurs through conserved single or paired sites [46] and the presence of conserved sites for other

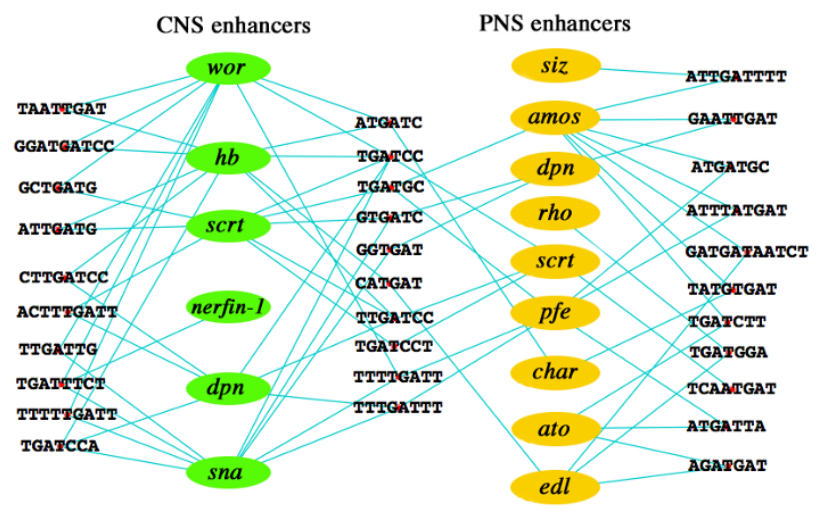

\section{Figure 2}

Shared cDTs that contain Pbx/Extradenticle core DNA-binding sites. Cytoscape analysis of shared $\mathrm{Pbx} /$ Extradenticle DNA-binding site (TGAT) containing CDT elements present in CNS NB and/or PNS enhancers. CDTs flanking the enhancer names are shared by CSBs of a single enhancer type, and CDTs positioned between the enhancer names are shared in common by CSBs of the two different enhancer types. 
transcription regulators associated with CSBs containing $\mathrm{Su}(\mathrm{H})$ binding sites has been documented [47].

Within the CSBs of the six NB enhancers examined, only two, $d p n$ and wor, contained conserved putative $\mathrm{Su}(\mathrm{H})$ binding sites; two dpn sites matched one of the $\mathrm{Su}(\mathrm{H})$ consensus sites (GTGGGAA) and two wor sites match the sequence ATGGGAA. Only one of the two dpn sites contained flanking bases conforming to the widely distributed CGTGGGAA site of $\mathrm{E}(\mathrm{spl}) \mathrm{Su}(\mathrm{H})$ binding sites and none of the $\mathrm{NB}$ enhancers contained paired $\mathrm{Su}(\mathrm{H})$ sites typical of the $\mathrm{E}(\mathrm{spl})$ enhancers $[25,46]$. Of the 13 PNS cisregulatory regions examined, only four enhancers contained putative $\mathrm{Su}(\mathrm{H})$-binding sites $[$ sna and ato (ATGGGAA), brd (GTGGGAG)] and $d p n$ (GTGGGAA). $d p n$ also contained a pair of sites that conforms to the SPS configuration frequently found in $\mathrm{Su}(\mathrm{H})$ enhancers (CSB sequence: AATGTGAGAAAAAAACTTTCTCACGATCAC$\mathrm{CTT}, \mathrm{Su}(\mathrm{H})$ sites in bold, Pbx site is ATCA). The lack of $\mathrm{Su}(\mathrm{H})$ sites in PNS enhancers was noted by Reeves and Posakony [23], who suggested that these enhancers are directly regulated by the proneural proteins but not activated in response to Notch-mediated lateral inhibitory signaling. Among the conserved sequences of $\mathrm{E}(\mathrm{spl})$ gene enhancers there is an average of 3.4 consensus $\mathrm{Su}(\mathrm{H})$ binding sites per enhancer, with most enhancers containing both types of sites, i.e., those with either A or G in the central position (data not shown).

We offer three insights with respect to $\mathrm{Su}(\mathrm{H})$ binding sites. First, although in vitro DNA-binding studies suggest there is a flexibility in the $\mathrm{Su}(\mathrm{H})$ binding site, like the bHLH Ebox, comparative analysis shows that within any one the $\mathrm{Su}(\mathrm{H})$ sites there is no sequence flexibility. Except for the pair of $\mathrm{Su}(\mathrm{H})$ sites in the dpn PNS enhancer, none of the CNS or PNS sites contained a central A; less that a quarter of the $\mathrm{E}(\mathrm{spl})$ sites consisted of a central $\mathrm{A}$, and all these were conserved across all species examined. In light of the high conservation in these regions the invariant core and flanking sequences are important for the unique $\mathrm{Su}(\mathrm{H})$ function at any particular site.

A second finding was the extensive conservation of bases flanking the consensus $\mathrm{Su}(\mathrm{H})$ sequence in the $\mathrm{E}(\mathrm{spl}) \mathrm{com}$ plex genes (data not shown). For example, the $c \mathrm{DT}$ GTGGGAAACACACGAC [Su(H) site bold] was present in HLHm3 and HLHm5 enhancer CSBs, and ACCGTGGGAAAC was conserved in HLHm3 and $H L H m \beta$ enhancers. The conservation of bases flanking the consensus $\mathrm{Su}(\mathrm{H})$ binding site suggests that the $\mathrm{Su}(\mathrm{H})$ site may be flanked by additional binding sites for co-operative or competitive factors, or else, that $\mathrm{Su}(\mathrm{H})$ contacts additional bases besides the consensus heptamer.

A third observation is that in most cases $\mathrm{Su}(\mathrm{H})$ binding sites are imbedded in larger CSBs, suggesting that CSB function is regulated by the integrated function of multiple TFs. For example the $d p n$ NB enhancer $\mathrm{Su}(\mathrm{H})$ site is imbedded in a CSB of 24 bases, and the atonal PNS enhancer $\mathrm{Su}(\mathrm{H})$ site is imbedded in a CSB of 45 bases. In the $\mathrm{E}(\mathrm{spl})$ complex, CSB \#6 of HLHm $\gamma$, consisting of 30 bases and CSB\#13 of m8, consisting of 31 bases (each contains a GTGGGAA $\mathrm{Su}(\mathrm{H})$ site, a CACGAG element, conforming to a Hairy N-box consensus CACNAG $[48,49]$, and an AGGA Tramtrack (Ttk) DNA-binding core recognition sequence [50], but the order and context of these three sites is different for each enhancer). Although $\mathrm{Su}(\mathrm{H})$ binding sites were present in only a minority of NB and PNS enhancers, the conservation of core bases, as well as the complexity of their flanking conserved sequences points to a diversity of $\mathrm{Su}(\mathrm{H})$ function and interaction with other factors.

\section{Neural specific cDTs that contain core DNA-binding sites for other known TFs}

Two of these elements, one exclusively present in NB enhancers (CAGGATA) and a second exclusively present in PNS enhancers (GTAGGA), contained consensus core

Table 3: Conserved bHLH binding sites in NB and PNS enhancer cis-Decoder tags

\begin{tabular}{|c|c|c|c|c|c|c|c|c|c|c|c|c|c|c|c|c|c|c|c|}
\hline \multirow[t]{2}{*}{ CANNTG E-box } & \multicolumn{6}{|c|}{ CNS Neural Precursor Cell Enhancers } & \multicolumn{13}{|c|}{ PNS Neural Precursor Cell Enhancers } \\
\hline & $d p n$ & $h b$ & $n f-I$ & scrt & sna & wor & $a c$ & amos & ato & brd & char & $d p n$ & edl & $p f e$ & rho & sc & scrt & siz & sna \\
\hline CAGCTG & 2 & - & 3 & 4 & - & 5 & - & - & - & - & 3 & - & 2 & 2 & 2 & 1 & I & - & - \\
\hline CAGGTG & - & - & - & - & I & 1 & 1 & - & 1 & I & 1 & - & 1 & - & - & 1 & 2 & 1 & - \\
\hline CAGATG & - & - & - & - & - & - & - & - & - & - & - & - & I & - & I & - & I & 2 & 1 \\
\hline CAAATG & I & - & - & 4 & - & 2 & 2 & 2 & 1 & - & - & - & 2 & - & - & - & - & - & I \\
\hline CAATTG & - & - & - & - & - & I & - & - & 2 & - & - & - & - & - & - & - & - & - & - \\
\hline CAACTG & - & - & - & I & - & - & - & - & - & - & - & - & - & - & - & - & I & - & - \\
\hline CAAGTG & - & I & - & 3 & 1 & 3 & 2 & I & I & - & - & - & - & - & - & - & I & 1 & - \\
\hline CATGTG & - & I & - & I & - & - & - & - & - & I & I & - & - & - & - & - & - & - & - \\
\hline CATATG & - & - & - & - & - & - & - & - & - & - & - & - & - & - & - & - & I & - & - \\
\hline CACGTG & - & - & I & - & - & 2 & - & - & 2 & I & - & I & - & - & I & - & - & - & I \\
\hline
\end{tabular}


AGGA DNA-binding sites for Ttk [50], a BTB domain TF that has been shown to regulate pair rule genes during segmentation and to repress neural cell fates [51-53]. Another site (CACCCCA), shared by both NB and PNS enhancers, conforms to the consensus binding site of IA1 (ACCCCA), the vertebrate homolog of nerfin-1 [54]. Most of the cDTs of Table 2 do not contain sequences corresponding to consensus binding-sites of known regulators of NB expression. The fact that they are represented multiple times in NB CSB sequences suggests that they contain binding sites for unknown regulators of neurogenesis in Drosophila.

\section{Neural-enriched cDTs}

Neural enriched $c$ DTs that are shared between multiple NB enhancers and also exhibit a low frequency in the sample of mesodermal enhancers examined in this study serve as a resource for understanding enhancer elements that may not have an exclusive neural function [see Additional file 1]. Notable here is the presence of CAGCTG bHLH DNA binding sites (all with flanking A, CC and TC) and Antennapedia class homeobox (Hox) core DNA binding site ATTA [40], as well as additional Ttk and Pbx/Extradenticle sites. Present in this list are portions of sequences conforming to $\mathrm{Su}(\mathrm{H})$ binding sites described above. Of particular interest in this table are sequences that are also enriched in the PNS (p); these sites may bind factors that play similar developmental roles in different tissues. For example, the presumptive Ttk site, AAAGGA (core sequence in bold) is highly enriched in segmental enhancers. Thus, some of these sites can be identified as targets of known TFs, but the identity of most are as yet unknown. These elements shared by multiple enhancers may be use-

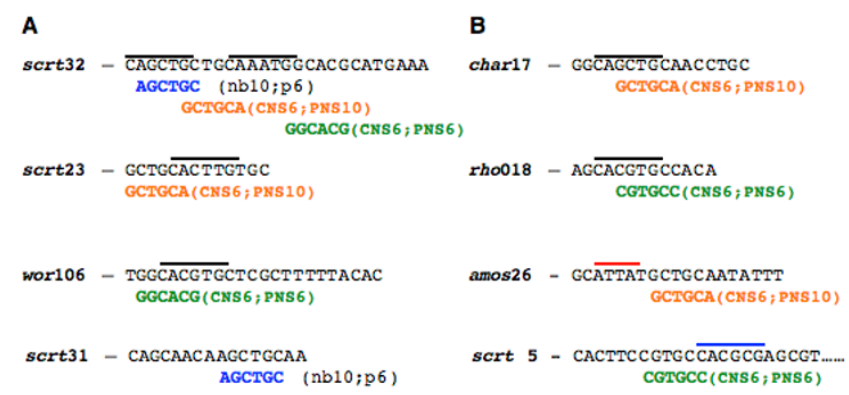

\section{Figure 3}

Shared sequence elements are found in different orientations and patterns within CSBs of neural precursor cell enhancers. Shown are CSBs from CNS (A) and PNS (B) enhancers aligned to three different frequently found neural specific or enriched cDTs. Shown in parentheses is the number of appearances of each CDT among CNS NB enhancers (nb), and PNS enhancers (p). Putative bHLH, Hox and Hairy TFDNA-binding sites are over-lined black, red or blue, respectively. ful in identifying other enhancers driving expression in NBs.

\section{cis-Decoder analysis reveals a complex sub-structure of enhancer CSBs}

EvoPrint analysis revealed that all of the enhancer regions examined in this study contained multiple CSBs that were greater that 15 to 20 bases in length. The occurrence of overlapping DNA-binding sites for different TFs is currently the best explanation for the maintenance of intact CSB sequences across $\sim 160$ millions of years of collective species divergence. Our analysis has revealed that the sequence context, order and orientation of shared $c \mathrm{DTs}$ can differ between co-regulating enhancers.

Two examples are given here of the complex contextual appearance of $c$ DTs that appear frequently in CNS and PNS enhancers (Figure 3). Each of the eight CSBs shown was nearly fully 'covered' by $c$ DTs of the NB library (data not shown), suggesting that each contains multiple overlapping binding sites for a number of TFs. First, examination of the distribution of $c$ DT GCTGCA reveals that it overlaps, by one and two bases, adjacent but different consensus bHLH sites in scrt CSB $\# 32$, while in scrt $\mathrm{CSB}^{\#} 23$ it overlaps a third consensus bHLH sequence by two bases. In the PNS enhancer char, in CSB\#17, GCTGCA overlaps a bHLH site, but in a different configuration (overlapping four bases) than found in the two CNS enhancers illustrated in Figure 3A. In amos CSB\#26, GCTGCA appears adjacent to a HOX site and does not overlap a bHLH site. Second, examination of the distribution of the $c$ DT GGCACG reveals that it overlaps different consensus bHLH sites in scrt CSB\#32 and wor $\mathrm{CSB}^{\#} 106$, overlapping the bHLH site in the former by one base and in the latter by four bases. GGCACG overlaps a CAGCTG bHLHbinding site in rho $\mathrm{CSB}^{\# 18} 18$, but in a different configuration than the overlap with CAGCTG in the wor CSB. In the PNS enhancer scrt, GGCACG in $\mathrm{CSB}^{\#} 5$ overlaps a Hairy site N-box (consensus CACNAG) [48,49]. N-boxes were most common in $\mathrm{E}(\mathrm{spl}) \mathrm{CSBs}$, but were also present in NB and PNS enhancer CSBs. In these two examples, and others we have examined, there is no consistent spatial constraints to the association of known TF-binding sites (i.e.,

Table 4: Co-appearance of TF binding sites within CSBs and in adjacent CSBs.

\begin{tabular}{lllll}
\hline & $\mathrm{Pbx}$ & bHLH & Hox & $\mathrm{Su}(\mathrm{H})$ \\
\hline $\mathrm{Pbx}$ & $5 / 6^{*}$ & - & - & - \\
$\mathrm{bHLH}$ & $6 / 12$ & $2 / 4$ & - & - \\
$\mathrm{Hox}$ & $9 / 14$ & $3 / 12$ & $10 / 23$ & - \\
$\mathrm{Su}(\mathrm{H})$ & $0 / 2$ & $0 / 0$ & $1 / 3$ & $0 / 0$ \\
Total & 47 & 36 & 57 & 3 \\
\hline
\end{tabular}

*First and second numbers represent appearance on same and adjacent CSBs, respectively. 
bHLH-binding E-box sites) with novel $c$ DTs; a picture that emerges is one of combinatorial complexity, in which known or novel $c$ DTs are associated with each other in different contexts on different CSBs.

As an initial step toward determining if different TFs interacted with one another or competed for flanking DNAbinding sites, we examined the proximity of known binding sites to one another in CSBs for bHLH, Hox, Pbx and $\mathrm{Su}(\mathrm{H})$. The results of this analysis for NB CSBs are shown in Table 4; data for other enhancer types is summarized here. Most striking was the presence of multiple adjacent Hox ATTA sites (10 instances on NB CSBs) and combinations of Hox and Pbx sites ( 9 instances NB CSBs). A typical example is the association of one Pbx site, a bHLH site and two Hox sites on a wor NB enhancer CSB (AATCATTTGTAATAATTAG; Pbx site is ATCA, Hox sites are TAAT and ATTA, and bHLH site is bold). Associations of Hox and Pbx sites was also apparent in PNS enhancer CSBs, and in addition there was a high level of combined Hox and bHLH sites (11 instances on PNS CSBs), but in E(spl) enhancers only a higher level of the combination of Hox and $\mathrm{Pbx}$ sites (8 instances) was apparent. An example of the association of Hox and bHLH sites in a PNS enhancer is found in an achaete-scute dorso-central enhancer CSB (CAAAACAACACTTGCTCTATTAAC; bHLH site in bold and Hox site is ATTA). There was also a distinctly higher level of Pbx sites on the same CSBs as bHLH sites in NBs CSBs (6 instances), but this combination was not apparent for PNS or E(spl) CSBs. Association of bHLH sites with $\mathrm{Su}(\mathrm{H})$ binding sites was apparent in $\mathrm{E}(\mathrm{spl})$ enhancer CSBs, especially when presence on adjacent CSBs (14 instances) was taken into account. Only in one of the 7 instances of paired $\mathrm{Su}(\mathrm{H})$ sites on $\mathrm{E}(\mathrm{spl})$ enhancers were these sites on the same CSBs, while in four other instances they were on adjacent CSBs. Although we often find sites in close proximity, both known and functionally uncharacterized sites are, with a few exceptions, not present in fixed uniform orientation in similarly regulated enhancers. This highlights the complex combinatorial arrangement and position flexibility of TF-binding sites within enhancer CSBs.

\section{The use of cis-Decoder, FlyEnhancer and EvoPrinter to identify novel enhancers}

We have used the information derived from cis-Decoder analysis of neural precursor cell enhancers to search for other genomic sequences with similar cis-regulatory properties. Having identified $c$ DTs found multiple times among NB enhancers, we used the genomic search tool FlyEnhancer [55] to identify Drosophila melanogaster genomic sequences that contained clusters of the following $c \mathrm{DTs}$ (number in parenthesis is the total number of each $c$ DT in our sample of six NB enhancers): GGCACG (6), GGAATC (4), TGACAG (6), TGGGGT (4), CAGCTG
(14), TGATTT (9) CAAGTG (7), CATATTT (5), TGATCC (7) and CTAAGC (6). As a lower limit, a minimum of three CAGCTG bHLH sites was set for this search, because of the prevalence of this site in nerfin-1 and deadpan NB enhancers. Each sequence detected by this search was subjected to EvoPrinter analysis to determine the extent of its sequence conservation. Among the $c \mathrm{DT}$ clusters identified, our search identified a 5 ' region adjacent to the nervy gene ([] that contained three conserved CAGCTG sites as well five other sites identical to TGACAG, GGAATC, TGGGGT, GGCACG and CATATTT (see below). nervy, originally identified as a target of homeotic gene regulation, is expressed in a subset of early CNS NBs, as well as in PNS SOP cells [56]. Later studies have implicated nervy, along with cyclic adenosine monophosphate (CAMP)dependent protein kinase (PKA) in antagonizing Sema1a-PlexA-mediated axonal repulsion [57], and nervy has been shown to promote mechanosensory organ development by enhancing Notch signaling [58].

EvoPrinter analysis revealed that the cluster of neural precursor cell enhancer $c$ DTs positioned 90 bp upstream from the nervy transcribed sequence contains highly conserved sequences (Figure 4A; chr2R:20,162,556$20,163,290)$. This region contains 10 CSBs that include six conserved E-boxes, three of which conform to the CAGCTG sequence that was prominent in nerfin-1 and deadpan promoters. To determine if this region functions as a neural precursor cell enhancer, we generated transformant lines containing the nervy CSB cluster linked to a minimal promoter/GFP reporter transgene (see methods section). Our analysis of the reporter expression driven by the nervy upstream fragment revealed a pattern indistinguishable from early nervy mRNA expression [56] (Figure 5). Specifically, we detected expression in a large subset of early delaminating NBs and in SOPs and secondary precursor cells of the PNS. Significantly, the nervy enhancer, unlike nerfin-1 and deadpan NB enhancers, activates reporter expression in then PNS and not just in early NBs.

A new $c$ DT-library was generated combining the nervy enhancer CSBs and the NB and PNS enhancer CSBs used to generate the libraries described above. The new $c \mathrm{DTs}$, along with the previously defined $c$ DTs were aligned back to nervy CSBs (Figure 4b). Most $c$ DTs were found only once in previously examined NB or PNS CSBs, but 21 cDTs appeared in our original analysis, described above, that did not include the nervy enhancer. The addition of this new enhancer to our analysis resulted in the discovery of a significant number of $c$ DTs that had not been found previously. Three $c$ DTs that were identified in the previous analysis, tCAGCTGc, cagCAGCTG and aaCAGCTG, contain bHLH DNA-binding sites (central bases of E-box in bold, flanking sequence are lower case). Aligning $c$ DTs that are specific to the CNS or PNS may indicate 
A

agcaggcgtagattgatggagccaccagatggccagccgggtgatgtgcatggccctagggacagatgtgtcaatcggtggctaattgc caatggccattgggatggttgacagacgggattggggccataaaataggtctagcgaagtctcaaccttaatctttaagccgaattta aataatatatattgctagtaagatgatgttcattaaactaatccttaaataatatcctaacaatatccctgcgcatcttgtagttccc tgctcaaatgaaccctataattgtggtgtaatccctggggaatcgaatgcactaacgagcaaatgtgtatctttaccacctctacctc tcgaactaattgctcttgaacgctgatctctaaagcctcgatgtgcccatttccaattggagatcccgcatggcatcgaagcgagccg aatcgcttccaatttgccagctccetgagatggggtggaccagagtcggtcggggtg tacctcctgAGCatTTGACATGGTGTGAACAC tCGCATAAGGCC $c t t a t c g c g t g c g g g g g a a a c c c c a a a g g g a g t$ GGG GTG $g$ GTGTGCACAATTGGTTGGCAATTTATTMAAATA

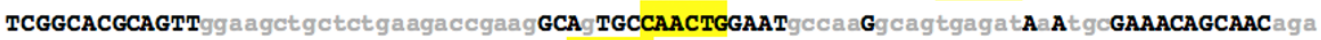
gagAA 9 CAAGCTGCTG $\subset$ C $\subseteq$ AAAaggaataggaaTTTTTCAGCTGCC $t$ tccagccagccaagtggcagggggtgcggtggaggggcgtct gagttcg GCAGCAGCTGATGTTAATAGCCCAG $\subset$ GGCC $a g g a g t g$ tctgcctgggctgcctggtctgcctgccetgccagt $t g t t g t g$

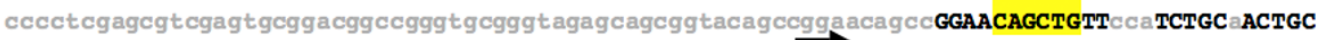
GCAGGCGCC CGaatCCGA $\subset$ cggatgcgtccgaacgccgctcggattgccgadcggagcggtcgaacatgtgctacctgggccgcagc accagcaccgcaactggcctcacaaacaaacgccacttacgactggtcggacgtgctcagctccgcggctcctcagttgtgcagttcaa tcgcatcggatactcgtatattcgcattcgcgtgttcgagcgcgccattcaagatagtcgagccgcagatactttcgcatccattcaga taccgattctgattttgattccgattcagtcgcttgccgttgctccgagatgccggttcgcgtttcgegctgcegcegccgttccgaca atgattcgatggtaaacaataacaaccactcacaagcggtcgccaagtgttaggtccagcgaaagcatctcgcagatagaatactaaat caagccacaagatacactccacctacgaagcgtcggaacagcagcgatctgccaaatggtgagtccatgcaaattgtat

B

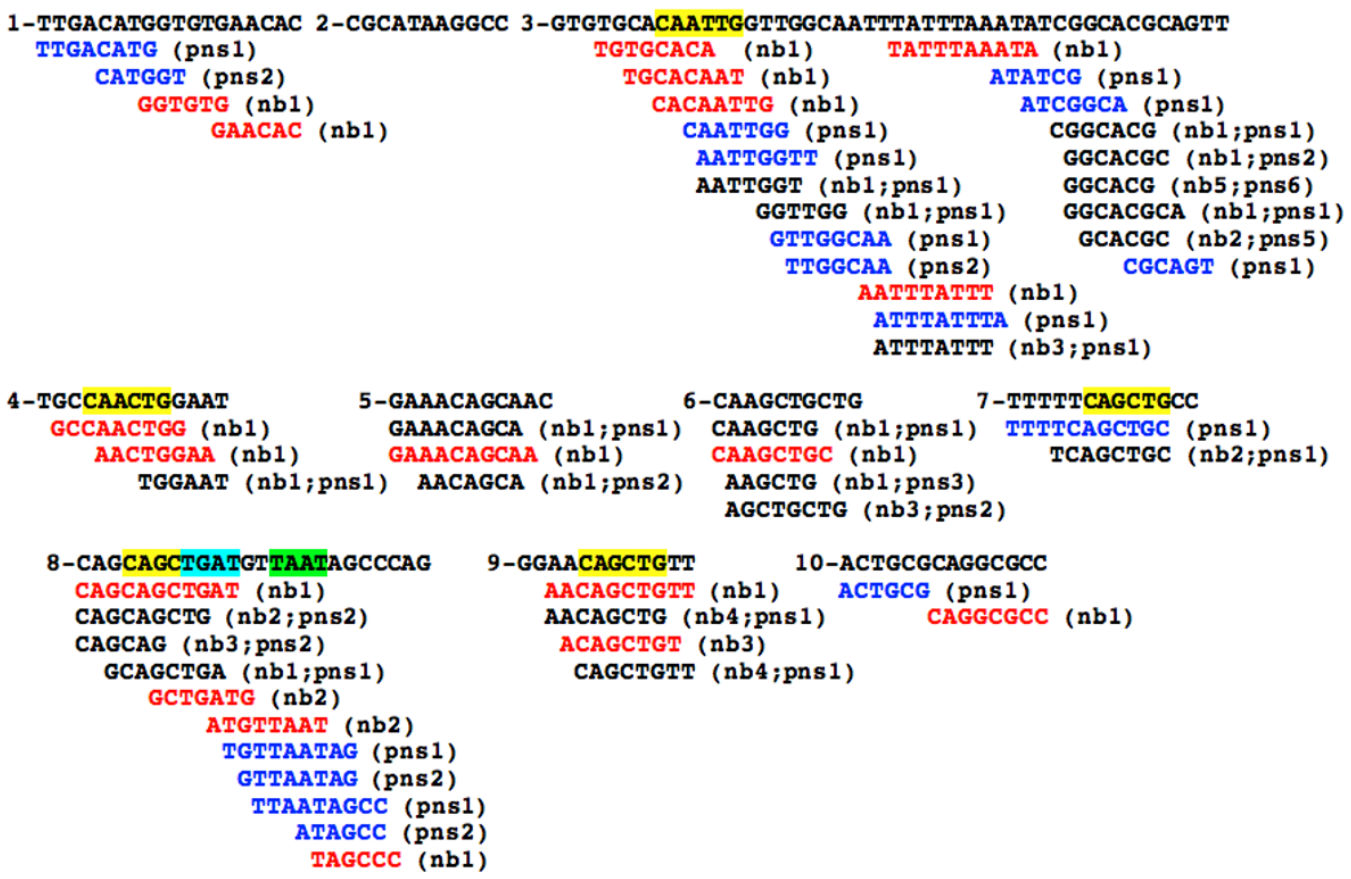

Figure 4

EvoPrinter and cis-Decoder analysis of the Drosophila nervy neural precursor cell enhancer region. EvoPrinter (A) and cis-Decoder (B) analysis of a nervy neural precursor cell enhancer positioned 90 bp upstream from the nervy transcriptional start site. A) Shown is an EvoPrint of the Drosophila melanogaster nervy gene 5' flanking DNA (487 bp). The predicted nervy transcriptional start site is denoted with an arrow. Test species included in the comparative analysis were $D$. simulans, $D$. sechellia, D. erecta, D. yakuba, D. ananassae, D. persimilis, D. pseudoobscura, D. willistoni and D. grimshawi. Black capital letters represent bases conserved in all, or all but one, species. Putative TFDNA-binding sites within the conserved sequences are highlighted (bHLH E-box sites, yellow; an Pbx/Extradenticle site, blue; and an Antennapedia class homeodomain binding site, green). B) Conserved sequence blocks identified in the nervy EvoPrint (A) were extracted and scanned for the presence of neural precursor cell enhancer CDTs. CDTs were generated using NB and PNS enhancer CSBs listed in Table I. cDTs generated by the inclusion of the nervy CSBs in the CDT library construction are also shown. CNS neuroblast specific cDTs are highlighted in red typeface, PNS precursor cell specific are noted with blue typeface and those present in both are indicated with black typeface (the number of enhancers that contain a CDT is also indicated). 
sequences required to specifically drive expression in either the CNS or PNS.

\section{Conclusion}

The major finding of this study is that enhancers of co-regulated genes in neural precursor cells possess complex combinatorial arrangements of highly conserved $c$ DT elements. Comparisons between NB and PNS enhancers identified CNS and PNS type-specific $c$ DTs and $c$ DTs that were enriched in one or another enhancer type. cisDecoder analysis also revealed that many of the conserved sequences contain DNA-binding sites for classical regulators of neurogenesis, including bHLH, Hox, Pbx, and $\mathrm{Su}(\mathrm{H})$ factors. Although in vitro DNA-binding studies have shown that many of these factors have a certain degree of flexibility in the sequences to which they bind, defined in terms of a position weight matrix [60], our studies show that for any given appearance these sites are actually highly conserved across all species of the Drosophila genus. The genus invariant conservation in many of these characterized binding sites indicates that there are distinct constraints to that sequence in terms of its function.
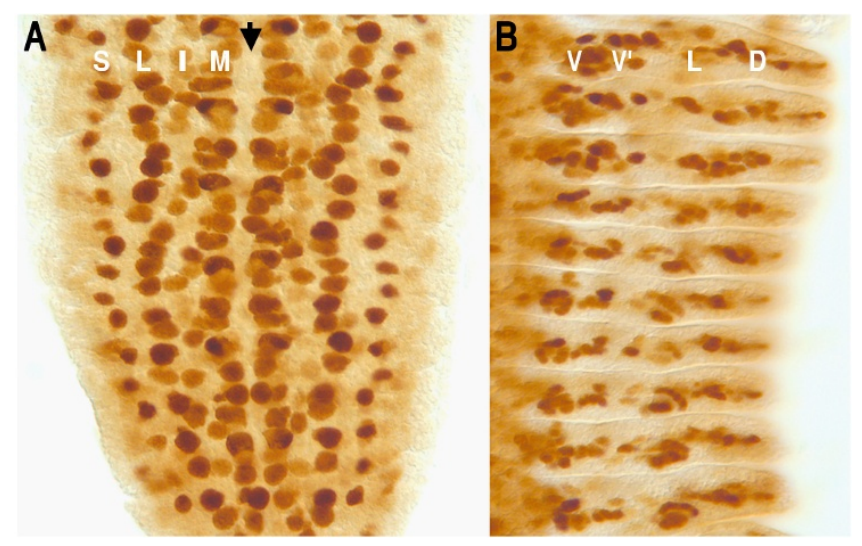

Figure 5

Expression pattern of the nervy enhancer-GFP reporter transgene during embryonic CNS and PNS development. Shown are GFP immunostains of stage 10 (A) and stage I3 (B) embryos from a transformant line that contains the nervy upstream genomic sequence (shown in Figure $4 \mathrm{~A}$ ) adjacent to a minimal promoter/GFP reporter transgene (anterior is up). A) During early nervous system development, GFP reporter expression is detected in CNS neuroblasts and in PNS sensory organ precursor cells. The letter $S$ indicates the PNS sensory organ precursor column and letters L, I, and M mark the lateral, intermediate and medial CNS neuroblast columns, respectively. Arrow indicates the ventral cord midline. B) GFP reporter expression is also detected in the secondary precursor cells of the developing PNS. Shown is the right half of the thoracic and abdominal segments. The letters $V, V$ ', $L$ and $D$ indicate the ventral, lateral and dorsal PNS neuronal cell clusters [59].
The high degree of conservation displayed in the enhancer CSBs could derive from unique sequence requirements of individual TFs, or the intertwined nature of multiple DNA-binding sites for different TFs. Thus there is a higher degree of biological specificity to these sites than the flexibility that is detected using in vitro DNA-binding studies. As an example, the requirement for a specific core for the bHLH binding site, i.e., for a CAGCTG E-box for nerfin-1, deadpan and nervy, suggests that it is the TF itself that demands sequence conservation; however, the requirement for conserved flanking sequences suggests that additional specific factors may be involved. Although the inter-species conservation of core and flanking sites has been noted by others [25], the extent of this conservation is rather surprising. To what extent and how evolutionary changes in enhancer function take place, given the conservation of core enhancer sequences, remains a question for future investigation.

In addition to classic regulators of neurogenesis, cisDecoder reveals additional conserved novel elements that are widely distributed or only detected in pairs of enhancers. Many of these novel elements flank known transcription binding motifs in one CSB, but appear independent of known motifs in another. The appearance of novel elements in multiple contexts suggests that they may represent DNA-binding sites for additional factors that are essential for enhancer function. Only through discovery of the factors binding these sequences will it become clear what role they play in enhancer function.

Preliminary functional analysis of CSBs within the nerfin1 neuroblast enhancer reveals that CSBs carry out different regulatory roles (Alexander Kuzin, unpublished results). Altering $c$ DT sequences within the nerfin-1 CSBs reveals that most are required for cell-specific activation or repression or for normal enhancer expression levels. CSB swapping studies reveals that, for the most part, the order and arrangement of a number of tested CSBs was not important for enhancer function in reporter studies. The discovery of the nervy neural enhancer by searching the genome with commonly occurring NB $c$ DTs underscores the potential use of EvoPrinter and cis-Decoder analysis for the identification of additional neural enhancers. By starting with known enhancers and building $c$ DT libraries from their CSBs, one now has the ability to search for other genes expressed during any biological event.

\section{Methods}

\section{Generation of EvoPrints and CSB-libraries}

EvoPrinter analysis was performed as described $[10,61]$. This analysis used EvoPrinterHD (please see Availability \& requirements for more information) a second-generation EvoPrinter program that uses an enhanced-BLAT algorithm for increased resolution of conserved sequences [61]. 
Detailed instructions are provided at the EvoPrinter web site.

When possible, all twelve Drosophila species were used for the EvoPrint analysis, while species that exhibited sequencing gaps were excluded. CSBs within enhancers were curated from either an EvoPrint, which reveals bases conserved in all species, or a relaxed print (also known as an EvoDifference profile) that identifies base pairs that are conserved in all but one of the species. The collective evolutionary divergence for all of the EvoPrints was greater than $140 \mathrm{My}$ and in most cases, when all twelve species were included in the analysis, EvoPrints represented over $\sim 200$ My of additive divergence. With the exception of two NB enhancers, scrt and wor, the size of each curated sequence was less than 1800 bases (Table 1). CSBs of $6 \mathrm{bp}$ or longer were extracted from the EvoPrints using EvoPrint parser to generate CSB libraries. The number of CSBs in each enhancer, enhancer length, and relation of the enhancer with respect to the transcriptional start site is shown in Table 1. Lists of CSBs for each library are given at the cis-Decoder web site (please see Availability \& requirements for more information).

\section{Generation of cis-Decoder Tag libraries}

In order to focus the analysis on neural-specific and neural-enriched $c$ DTs, those cDTs that were found at high frequency in non-neural (mesodermal) enhancers were placed in a shared/common $c$ DT-library. To identify neural specific $c$ DT elements, the frequency of $c$ DTs was scored against an out-group of mesodermal CSBs [11], and subsequently the common elements were removed. Prior to removal of mesodermal $c$ DTs, the number of NB $c$ DTs was 856 , whereas after removal of shared $c$ DTs, the number dropped to 272 , indicating that the majority of $c$ DTs shared by NB enhancers were also present in mesodermal enhancers.

Three $c$ DT-libraries were generated by alignment of NB, PNS and E(spl) CSBs and are provided at the cis-Decoder web site (please see Availability \& requirements for more information). The number of $c$ DTs in each library was 272,333 and 226 respectively. Of the $272 \mathrm{NB} c$ DTs, less than half (120) aligned exclusively with NB CSBs, and did not align with PNS or E(spl) CSB sequences. Only $21 \%$ of the NB $c$ DTs corresponded to PNS tags - in other words only $21 \%$ of the NB tags aligned two times or more with PNS CSBs.

\section{Cytoscape analysis}

We have adapted the biomolecular interaction network software Cytoscape [62] in order to display shared $c$ DTs from different enhancer CSBs. The following data structure was used: node $1 \mathrm{xx}$ node2, where node1 is the name of an enhancer, $x x$ refers to any designator and node 2 is the $c \mathrm{DT}$ sequence. This data structure facilitates the display of enhancer identity and shared sequence elements in an interactive pattern. Cytoscape analysis requires elimination of the reverse complements of $c$ DTs in order to avoid duplicate representation. To eliminate duplicate reverse-complement $c \mathrm{DTs}$, we used the program $c \mathrm{DT}$ Uncomplementer (please see Availability \& requirements for more information). After removing duplicates, $c$ DTcataloger was used to name each node according to the enhancer aligning with that $c$ DT.

\section{Identification of novel neural precursor cell enhancers}

To identify novel enhancers that direct gene expression in neural precursor cells, we curated $c$ DTs that were shared by multiple identified NB enhancers and submitted them to the web-based genomic search tool FlyEnhancer [55], to discover other genomic regions with similar densities of $c$ DTs. Candidate sequences that contained densities of $c$ DTs alignments were subject to EvoPrinterHD analysis to determine the extent of conservation. Candidate enhancer regions were selected for enhancer/reporter studies.

\section{Generation and analysis of nervy enhancer/reporter transformant lines}

Genomic DNA containing the putative nervy enhancer (734 bp) was amplified by PCR using standard methods. Primers for the nervy upstream region including BglII and Nhe1 sites (bold) were respectively AGATCTCTAAAGC CCTCGATGTGCCC (5') and GCTAGCTCCGACCAGTCGTAAGTGGCG (3'). Fragments were gel purified and cloned into the pCRII-TOPO double promoter vector. Sequencing verified the fidelity of the PCR and cloning. After cutting with Bgl and Nhe1, gel purification was performed and fragments were cloned into pH-Stinger [63]. Details of our procedure are available upon request. The generation of transformant lines and embryo immunohistochemistry were carried out as described previously [64].

\section{Availability \& requirements}

EvoPrinterHD: http://evoprinter.ninds.nih.gov/

cis-Decoder, $\quad$ CSB-libraries: http://evo printer.ninds.nih.gov/cisdecoder/csblibraries.htm

cis-Decoder, cDT-libraries: http://evo printer.ninds.nih.gov/cisdecoder/cdtlibraries.htm

cDT-Uncomplementer: http://evoprinter.ninds.nih.gov/ cisdecoder/uncomplementer.htm

\section{Authors' contributions}

WR and KB participated in the design and implementation of the algorithms. $\mathrm{AK}$ and $\mathrm{MK}$ participated in the cloning of enhancers. TB and WFO conceived of the study, participated in the design and coordination of the algo- 
rithms and prepared the manuscript. All authors have read and approved the final draft of the manuscript.

\section{Additional material}

\section{Additional file 1}

cis-Decoder tags with multiple hits on two or more NB enhancers. All are NB enriched with a low level of hits on mesoderm CSBs.

Click here for file

[http://www.biomedcentral.com/content/supplementary/1471-

2164-9-371-S1.doc]

\section{Acknowledgements}

The authors would like to thank Jermaine Ross and Antonios Ekatomatis for their technical assistance and Judith Brody for editorial expertise. This research was supported by the Intramural Research Program of the $\mathrm{NIH}$, NINDS.

\section{References}

I. Davidson EH: The regulatory genome; Gene regulatory networks in development and evolution. Burlington MA, Academic Press (Elsevier); 2006.

2. Levine M, Davidson EH: Gene regulatory networks for development. Proc Natl Acad Sci USA 2005, 102:4936-42.

3. Castro B, Barolo S, Bailey AM, Posakony JW: Lateral inhibition in proneural clusters: cis-regulatory logic and default repression by Suppressor of Hairless. Development 2005, I 32:3333-44.

4. Cave JW, Loh F, Surpris JW, Xia L, Caudy MA: A DNA transcription code for cell-specific gene activation by notch signaling. Curr Biol 2005, 15:94-104.

5. Kiefer JC, Jarman A, Johnson J: Pro-neural factors and neurogenesis. Dev Dyn 2005, 234:808-13.

6. Zhao G, Wheeler SR, Skeath JB: Genetic control of dorsoventral patterning and neuroblast specification in the Drosophila central nervous system. Int J Dev Biol 2007, 5 I: I07-15.

7. Campos-Ortega JA: Genetic mechanisms of early neurogenesis in Drosophila melanogaster. Mol Neurobiol 1995, 10:75-89.

8. Cornell RA, Ohlen TV: Vnd/nkx, ind/gsh, and msh/msx: conserved regulators of dorsoventral neural patterning? Curr Opin Neurobiol 2000, 10:63-7I.

9. Berman BP, Pfeiffer BD, Laverty TR, Salzberg SL, Rubin GM, Eisen MB Celniker SE: Computational identification of developmental enhancers: conservation and function of TFbinding-site clusters in Drosophila melanogaster and Drosophila pseudoobscura. Genome Biol 2004, 5:R6I.

10. Odenwald WF, Rasband W, Kuzin A, Brody T: EVOPRINTER, a multigenomic comparative tool for rapid identification of functionally important DNA. Proc Natl Acad Sci USA 2005, 102: 14700-5.

II. Brody T, Rasband W, Baler K, Kuzin A, Kundu M, Odenwald WF: cisDecoder discovers constellations of conserved DNA sequences shared among tissue-specific enhancers. Genome Biol 2007, 8:R75.

12. Hoch M, Schröder C, Seifert E, Jäckle H: cis-acting control elements for Krüppel expression in the Drosophila embryo. EMBO J 1990, 9:2587-2595.

13. Hoch M, Seifert E, Jäckle H: Gene expression mediated by cisacting sequences of the Kruppel gene in response to the Drosophila morphogens bicoid and hunchback. EMBO J I99I, 10:2267-78.

14. Hoch M, Gerwin N, Taubert $H$, Jäckle $H$ : Competition for overlapping sites in the regulatory region of the Drosophila gene Kruppel. Science 1992, 256:94-7.

15. Emery JF, Bier E: Specificity of CNS and PNS regulatory subelements comprising pan-neural enhancers of the deadpan and scratch genes is achieved by repression. Development 1995 , I 21:3549-3560.
16. Schröder C, Tautz D, Seifert E, Jäckle H: Differential regulation of the two transcripts from the Drosophila gap segmentation gene hunchback. EMBO J 1998, 7(9):288I-2887.

17. Ashraf SI, Ganguly A, Roote J, Ip YT: Worniu, a snail family zincfinger protein, is required for brain development in Drosophila. Dev Dynamics 2004, 231 :379-386.

18. Ip YT, Levine M, Bier E: Neurogenic expression of snail is controlled by separable CNS and PNS promoter elements. Development 1994, I 20:199-207.

19. García-García MJ, Ramain P, Simpson P, Modolell J: Different contributions of pannier and wingless to the patterning of the dorsal mesothorax of Drosophila. Development 1999, I 26:3523-3532

20. Holohan EE, zur Lage PI, Jarman AP: Multiple enhancers contribute to spatial but not temporal complexity in the expression of the proneural gene, amos. BMC Dev Biol 2006, 6:53.

21. Sun $Y$, Jan $L Y$, Jan $Y N$ : Transcriptional regulation of atonal during development of the Drosophila peripheral nervous system. Development 1998, I 25:3731-40.

22. Singson A, Leviten MW, Bang AG, Hua XH, Posakony JW: Direct downstream targets of proneural activators in the imaginal disc include genes involved in lateral inhibitory signaling. Genes Dev 1994, 8:2058-7I.

23. Reeves N, Posakony JW: Genetic programs activated by proneural proteins in the developing Drosophila PNS. Dev Cell 2005 , 8:4I3-425.

24. Culi J, Modolell J: Proneural gene self-stimulation in neural precursors: an essential mechanism for sense organ development that is regulated by Notch signaling. Genes Dev 1998, I 2:2036-47.

25. Nellesen DT, Lai EC, Posakony JW: Discrete enhancer elements mediate selective responsiveness of enhancer of split complex genes to common transcriptional activators. Dev Biol 1999, 21 3:33-53.

26. Lai EC, Bodner R, Posakony JW: The Enhancer of split complex of Drosophila includes four Notch-regulated members of the bearded gene family. Development 2000, I27:344|-55.

27. Bailey AM, Posakony JW: Suppressor of Hairless directly activates transcription of Enhancer of split complex genes in response to Notch receptor activity. Genes Dev 1995, 9:2609-2622.

28. Lecourtois M, Schweisguth F: The neurogenic Suppressor of Hairless DNA-binding protein mediates the transcriptional activation of the Enhancer of split complex genes triggered by Notch signaling. Genes Dev 1995, 9:2598-2608.

29. Akin ZN, Nazarali AJ: Hox genes and their candidate downstream targets in the developing central nervous system. Cell Mol Neurobiol 2005, 25:697-74I.

30. Sagerstrom CG: PbX marks the spot. Dev Cell 2004, 6:737-8.

31. Bertrand N, Castro DS, Guillemot F: Proneural genes and the specification of neural cell types. Nat Rev Neurosci 2002, 3:517-30.

32. Powell LM, zur Lage PI, Prentice DR, Senthinathan B, Jarman AP: The proneural proteins Atonal and Scute regulate neural target genes through different E-box binding sites. Mol Cell Biol 2004, 24:9517-26.

33. Jennings BH, Tyler DM, Bray SJ: Target specificities of Drosophila Enhancer of split basic helix-loop-helix proteins. Mol Cell Biol 1999, 19:4600-4610.

34. Morgenstern B, Atchley WR: Evolution of bHLH TFs: modular evolution by domain shuffling? Mol Biol Evol 1999, 16:1654-63.

35. Hughes CL, Kaufman TC: Hox genes and the evolution of the arthropod body plan. Evol Dev 2002, 4:459-99.

36. Prokop A, Bray S, Harrison E, Technau GM: Homeotic regulation of segment- specific differences in neuroblast numbers and proliferation in the Drosophila central nervous system. Mech Dev 1998, 74:99-II0.

37. Cenci C, Gould AP: Drosophila Grainyhead specifies late programmes of neural proliferation by regulating the mitotic activity and Hox-dependent apoptosis of neuroblasts. Development 2005, 132:3835-45.

38. Berger C, Pallavi SK, Prasad M, Shashidhara LS, Technau GM: A critical role for cyclin $E$ in cell fate determination in the central nervous system of Drosophila melanogaster. Nat Cell Biol 2005, 7:56-62. 
39. Bello B, Holbro N, Reichert H: Polycomb group genes are required for neural stem cell survival in postembryonic neurogenesis of Drosophila. Development 2007, I 34:109|-9.

40. Gehring WJ, Qian YQ, Billeter M, Furukubo-Tokunaga K, Schier AF, Resendez-Perez D, Affolter M, Otting G, Wüthrich K: Homeodomain-DNA recognition. Cell 1994, 78:2। I-23.

4I. Van Dijk MA, Voorhoeve PM, Murre C: PbxI is converted into a transcriptional activator upon acquiring the $\mathbf{N}$-terminal region of E2A in pre-B-cell acute lymphoblastoid leukemia. Proc Natl Acad Sci USA 1992, 90:606 I-5

42. Lu Q, Wright DD, Kamps MP: Fusion with E2A converts the Pbxl homeodomain protein into a constitutive transcriptional activator in human leukemias carrying the $t(1 ; 19)$ translocation. Mol Cell Biol 1994, I4:3938-48.

43. Moens $C B$, Selleri L: Hox cofactors in vertebrate development Dev Biol 2006, 29 I: 193-206.

44. Knoepfler PS, Lu Q, Kamps MP: Pbx-I Hox heterodimers bind DNA on inseparable half-sites that permit intrinsic DNA binding specificity of the Hox partner at nucleotides 3 ' to a TAAT motif. Nucleic Acids Res 1996, 24:2288-94

45. Bray $S$, Furriols $M$ : Notch pathway: making sense of suppressor of hairless. Curr Biol 200I, I I:R2 I7-2I.

46. Nam Y, Sliz P, Pear WS, Aster JC, Blacklow SC: Cooperative assembly of higher-order Notch complexes functions as a switch to induce transcription. Proc Natl Acad Sci USA 2007, 1 04:2103-8.

47. Maeder ML, Polansky BJ, Robson BE, Eastman DA: Phylogenetic footprinting analysis in the upstream regulatory regions of the Drosophila Enhancer of split genes. Genetics 2007, I 77:1377-94.

48. Klämbt C, Knust E, Tietze K, Campos-Ortega JA: Closely related transcripts encoded by the neurogenic gene complex enhancer of split of Drosophila melanogaster. EMBO J 1989, 8:203-10.

49. Tietze K, Oellers N, Knust E: Enhancer of split D. A dominant mutation of Drosophila, and its use in the study of functional domains of a helix-loop-helix protein. Proc Natl Acad Sci USA 1992, 89:6152-6156.

50. Fairall L, Schwabe JW, Chapman L, Finch JT, Rhodes D: The crystal structure of a two zinc-finger peptide reveals an extension to the rules for zinc-finger/DNA recognition. Nature 1993, 366:483-7.

5I. Guo M, Bier E, Jan LY, Jan YN: tramtrack acts downstream of numb to specify distinct daughter cell fates during asymmetric cell divisions in the Drosophila PNS. Neuron 1995, | 4:913-925

52. Giesen K, Hummel T, Stollewerk A, Harrison S, Travers A, Klambt C: Glial development in the Drosophila CNS requires concomitant activation of glial and repression of neuronal differentiation genes. Development 1997, I 24:2307-23 I6.

53. Badenhorst P, Finch IT, Travers AA: Tramtrack co-operates to prevent inappropriate neural development in Drosophila. Mech Dev 2002, I I 7:87-101.

54. Breslin MB, Zhu M, Notkins AL, Lan MS: Neuroendocrine differentiation factor, IA-I, is a transcriptional repressor and contains a specific DNA- binding domain: identification of consensus IA-I binding sequence. Nucleic Acid Res 2002, 30:1038-1045

55. Markstein M, Markstein P, Markstein V, Levine MS: Genome-wide analysis of clustered Dorsal binding sites identifies putative target genes in the Drosophila embryo. Proc Natl Acad Sci USA 2002, 99:763-8.

56. Feinstein PG, Kornfeld K, Hogness DS, Mann RS: Identification of homeotic target genes in Drosophila melanogaster including nervy, a proto-oncogene homologue. Genetics 1995, | 40:573-86.

57. Terman JR, Kolodkin AL: Nervy links protein kinase a to plexinmediated semaphorin repulsion. Science 2004, 303: I 204-7.

58. Wildonger J, Mann RS: Evidence that nervy, the Drosophila homolog of ETO/MTG8, promotes mechanosensory organ development by enhancing Notch signaling. Dev Biol 2005, 286:507-20.

59. Brewster R, Bodmer R: Origin and specification of type II sensory neurons in Drosophila. Development 1995, I 2 1:2923-36.
60. Down TA, Bergman CM, Su J, Hubbard T]: Large-scale discovery of promoter motifs in Drosophila melanogaster. PLoS Comput Biol 2007, 3:e7.

61. Yavatkar A, Lin Y, Ross J, Fann Y, Brody T, Odenwald WF: Rapid detection and curation of conserved DNA via enhancedBLAT and EvoPrinterHD analysis. BMC Genomics 2008, 9: 106

62. Shannon P, Markiel A, Ozier O, Baliga NS, Wang JT, Ramage D, Amin $\mathrm{N}$, Schwikowski B, Ideker T: Cytoscape: a software environment for integrated models of biomolecular interaction networks. Genome Res 2003, I 3:2498-504.

63. Barolo S, Castro B, Posakony JW: New Drosophila transgenic reporters: insulated P-element vectors expressing fastmaturing RFP. Biotechniques 2004, 36:436-40,442.

64. Kuzin A, Kundu M, Brody T, Odenwald WF: The Drosophila nerfinI mRNA requires multiple microRNAs to regulate its spatial and temporal translation dynamics in the developing nervous system. Dev Biol 2007, 3 1 0:35-43.

Publish with BioMed Central and every scientist can read your work free of charge

"BioMed Central will be the most significant development for disseminating the results of biomedical research in our lifetime. "

Sir Paul Nurse, Cancer Research UK

Your research papers will be:

- available free of charge to the entire biomedical community

- peer reviewed and published immediately upon acceptance

- cited in PubMed and archived on PubMed Central

- yours - you keep the copyright
BioMedcentral 